Portland State University

PDXScholar

5-15-1996

\title{
Songs and Stories that Only You Know: Multiplicity, Meaning, \& the Metaphorical Bridge
}

Matthew Haggett

Portland State University

Follow this and additional works at: https://pdxscholar.library.pdx.edu/open_access_etds

Part of the Fine Arts Commons, and the Painting Commons Let us know how access to this document benefits you.

Recommended Citation

Haggett, Matthew, "Songs and Stories that Only You Know: Multiplicity, Meaning, \& the Metaphorical Bridge" (1996). Dissertations and Theses. Paper 5191.

https://doi.org/10.15760/etd.7067

This Thesis is brought to you for free and open access. It has been accepted for inclusion in Dissertations and Theses by an authorized administrator of PDXScholar. Please contact us if we can make this document more accessible: pdxscholar@pdx.edu. 


\section{THESIS APPROVAL}

The abstract and thesis of Matthew Haggett for the Master of Fine Arts in Art:

Painting were presented May 15, 1996, and accepted by the thesis committee and the department.

COMMITTEE APPROVALS:

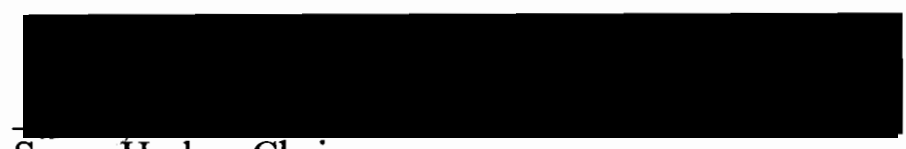

Susan Harlan, Chair

Eleanor Erskine
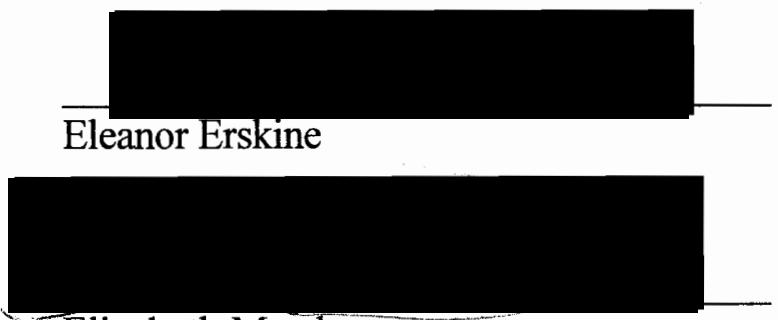

Elizabeth Mead

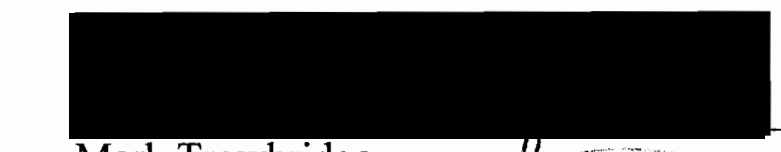

Mark Trowbridge
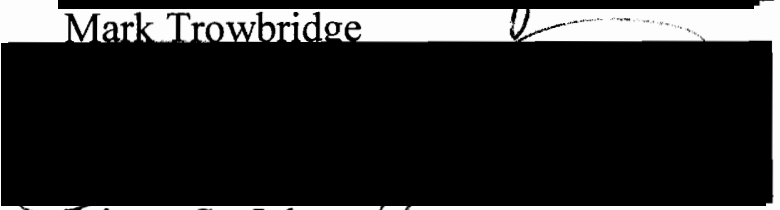

Primus St. John

Representative of the Office of

Graduate Studies

DEPARTMENT APPROVAL:

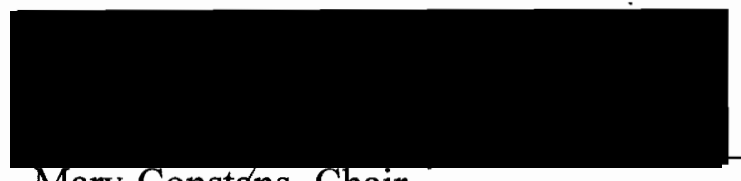

Mary Constăns, Chair

Department of Art

ACCEPTED FOR PORTLAND STATE UNIVERSITY BY THE LIBRARY

by

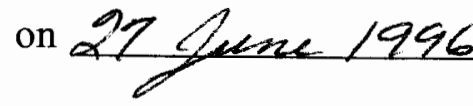




\begin{abstract}
An abstract of the thesis of Matthew Haggett for the Master of Fine Arts in Art: Painting presented May 15, 1996
\end{abstract}

Title: Songs and Stories That Only You Know: Multiplicity, Meaning, \& the Metaphorical Bridge.

The thesis report will serve as a companion for the body of work that is the bulk of the thesis project. The theme of the thesis project is "the bridge". "The bridge" is a metaphor for meaning occurring through context. It is present on many levels. It will implicit in much of the discussion. I will include themes such as the play of differing scales, the ambiguous line between part and whole, and the reasons for the book format .

Specific imagery that occurs repeatedly in the work, like architecture and knots, will be explained in terms of its sources, personal meaning, and formal and conceptual roles. My interests in poetry is also a necessary topic as poetry is both present in the thesis work and implicit in my ideas about art as language.

The thesis report will be secondary to the thesis work. It is of primary importance that the work can stand on its own. The ideas discussed in the thesis report must be accessible through the work itself (to a greater or lesser 
degree). To this effect, the thesis report will not be an attempt to convince, coerce, or cajole the unswayed viewer. 
SONGS AND STORIES

THAT ONLY YOU KNOW:

MULTIPLICITY, MEANING

\& THE METAPHORICAL BRIDGE

by

MATTHEW HAGGETT

A thesis submitted in partial fulfillment of the requirements for the degree of

MASTER OF FINE ARTS

in

ART: PAINTING

Portland State University

1996 
Part One:

Introduction

My work is more of an interrogation of the possibilities than an assertion of the known. Meaning is elusive. The harder you look at the border between sense and nonsense, the more convoluted it appears to be. In my work, I ask "can it be the case that X?" and "can it be the case that Y?" I set up systems then undermine them to see how they fall apart.

"In some bodies of work, it is the similarities that hold it together. In others, it is the differences." 1

My art is about multiplicity and difference. It is about a shifting sense of place and the contextuality of meaning. To approach these issues, I use the absence of a framework as a frame work. I try to reduce common denominators and push the work in dramatically different directions. The formats in this show include painting, sculpture, book art, and poetry. The styles I use shift from abstraction to representation, from symbolic to narrative, from haphazard to precise, from formal to conceptual. The divisions between all these aspects is not clean. 
This body of work is meant to imply a system of which all the pieces are possible outcomes. The pieces are marks that make a larger piece (figure 1). They feed into the context of the whole installation and are altered by that context. I am aiming for an experience that does not resolve.

In this report, I will discuss my approach to art as a linguistic system, the shifting sense of place, the tenor of decay, the multiple rectangle format of the paintings, the use of the book format, and the formal and conceptual roles of a few images that recur in the work.

But before going any further... 
Part Two:

The Rational and Non-rational

In The Bacchae by Euripides, a cocky young king forbids the worship of Dionysus in his kingdom. Dionysus gets mad and extracts a grueling and gory vengeance on the king and his family. There is much death, dismemberment, and madness. When all is said and done, it seems like a bad idea to deny Dionysus.

Dionysus does not just represent drinking wine and lounging around on cushions. Dionysus stands for the trans- or non-rational. He is the polar opposite of Apollo, who embodies the power of reason. In the context of this duality, the young king from The Bacchae was trying to deny the force of the irrational and put all his chips on the power of rationality. For this, he paid the ultimate price.

This morality play (if you'd call it that) is pertinent. While I can discuss certain formal tactics, inspirations, and ideas this language is a construct of reason. To the extent that my art crosses into the nonrational, parts of it are beyond textual containment. Sense and nonsense are interwoven. The essential thing lies beyond the domain in which text is a useful map. The work makes visual sense that can not be distilled into words. If I fancied that I could capture it here, I'd be denying Dionysus. And where would that get me?

The map is not the territory. The menu is not the meal. 
Part Three:

Language

How does meaning occur? Where does meaning enter and where does it enter from? Meaning is not inherent in any given thing. It lies in the bridges between unlike things. ${ }^{2}$

Meaning is like a spark jumping between differently charged objects. The further apart the objects and the more different their charges, the greater the spark. In this text meaning emerges in a fairly smooth manner. There is a constant hum of little sparks jumping between letters, words, phrases, sentences, etc. The regularity of syntax and logical progression holds it together. The process is linear.

In the language of my visual art, I aim for non-linear connections. I treat its language poetically. The linguistic elements are pushed apart. Sparks of meaning occur differently. There are multiple readings possible in each piece and in the various connections between pieces. The signs and symbols are allowed to randomly push and pull on one another; they spin and collide.

In While We Were Sleeping (figure 2), an equation is drawn between several disparate elements. Interlocked fingers of two hands have something to do with an empty frame. The "hands" are also a lattice of red lines on a defaced pullout shelf. The hinges with which the empty frame is attached echo the hinges on a nearby box. The empty frame echoes a similar empty frame in Tiny Catastrophes (figure 3). And it is called "while we were sleeping." What does this all add up to? 
Any explanation I could offer is irrelevant. If meaning is perceived then there it is. It is subjective, hinging entirely on the viewer's mental processes.

Poetic construction strips down the process with which context creates meaning. It undermines the formal self-consistency of the language that is uses. It undermines the idea that language has a 1:1 relationship with some exterior state of affairs. 


\section{Part Four:}

Place

The boundary between flat, self-contained painting and three dimensional, sculptural object is pushed and broken down. The pieces evoke multiple senses of place.

The work goes through a gradual dissection of framedness and containment. Place is approached as symbol and memory in Back from After (figure 4). Its composition is iconic. Fragments of language surround a distant building. The piece's frame separates it from the gallery space. Place is put in quotes. It is fully elsewhere.

The quotes are gradually dissolved. In A Song for the Hawthorne Bridge (figure 5), place is approached more (a little more) representationally. The bridgelike structure is based on observation rather than symbolism. But that representation blends with visceral, physical surfaces and abstract evocation of space. The "elsewhere" that representation and symbolism talk about is undermined by the "right here" of physical presence.

Painting segues into thing (or thing into painting). The floor of the room is occupied by books and objects. Objects hang off painting surfaces, suspended by steel devices that echo the steel book stands. Imagery in the paintings and their all pervasive rectangularity echo the stands and objects in the floor space. The "content" of the books refers in part to the paintings and vice versa.

Threshold (figure 6) is a pivotal station along this motion. While the surface of the painting blends illusionary depth with visceral physical surfaces, a low bench in front of the piece presents a roughly conical sculrtural object. The 
space the object evokes is directly referent to the viewer's own occupation of space. Its spatial statement combines and recombines with the illusionary and abstract space of the painting into a heightened state of ambiguity. It moves off the wall onto the floor.

The books and boxes (Figure 7,8, \& 9) talk directly about the viewer's physical presence. Books refer to the scale of the hand or the arm. They require active participation and create an intimate experience. Books break down the barrier between viewer and art. While it is generally a faux pas to fondle paintings in an art gallery, the artist's book demands to be handled.

In terms of place, the book experience doubles back on itself. While directly involving the viewer's body (asserting "here"), it is also telling a story (asserting "elsewhere").

How is one's detached experience with a painting altered by the hands-on experience of a book? How is the "inside" of a painting like the "inside" of a book? How does a volumetric objects assertion of presence effect the illusionary presence of a represented place? The books, objects, and paintings combine into a shifting sense of location (and dislocation.) Rough division is possible but the line between here and elsewhere is imprecise.

A sense of place is approached from different directions because our minds process location in different ways. Perception is a shifty thing. Whether or not oneness underlies the world, multiplicity dominates our experience. 
Part Five:

Multiplicity

In the words of Hassan i Sabbah (The old man of the mountain, The grandfather of assassins) "Nothing is true. Everything is permitted." 3 Though not unrelated, the work does not strive towards a common goal. It does not represent a reduction towards an absolute or essential but rather a motion the labyrinth of signs.

I'm skeptical about absolutes and essentials. I'm not all that interested in the truth. If the truth is there, it is event horizons away.

I'm interested in the world and the maps we use to approach it. The world is multiplicitous and ambiguous. The maps we make close in on it but never quite reach it. The world comes up with radically different solutions at different scales, speeds, temperatures and pressures. There are many truths that support themselves and exclude one another. What is true in one context is untrue in another.

I'm building with holes.

I'm always trying to backtrack and insert cancelation before the fact. I'm trying to say two things that make each other the opposite of themselves. Or two things at once so that their overlap seems like another story all together. 
Part Six:

Decay

For all the differences, this body of work has an overall tenor of ancientness and decay. It speaks of some kind of history. This atmosphere does not stem from nostalgia but rather from my interest in the deterioration of old information systems and the emergence of new systems.

Use and meaning remain in ruins as a sort of residue.

I am drawn to things that have graduated from their initial function and moved into a state of obscurity. I am inspired by walls engaged in the long process of decay and repair, defacement and retouching. A window is bricked over. A connecting building is demolished. The surface is graffitied and the graffiti is covered over. The process has no outcome in mind. It is unconscious and accidental: pure residue. Events and processes are recorded.

Layers of information build up in my work. Earlier things are stripped away or covered. Intermediate steps between one piece and the next are edited out. Accident is embraced. The layer that will be hidden contains its own internal logic. The layer that hides it has a logic that reflects that which is lost. For all the degradation, the earliest ideas, the initial impulses, even if they are totally removed from the finished piece, still linger in these surfaces. 
Part Seven:

Rectangles

The rectangle is a convention of painting used self-consciously. It is a meaningful statement (implying wholeness, separation, and containment) rather than an unquestioned axiom or a background on which the work is built. By juxtaposing rectangles in single pieces (as in Dis, figure 10), correlations are drawn between the lesser pieces that make up the whole piece. Countering the closed rectangle's statement of self-containment, these juxtapositions assert connectedness. The constituent pieces (such as the steel framed globe) are "whole" but inseparable from one another.

This serves to further question the independence of all the pieces in this installation.

I have explored multiple rectangular configurations in several ways: equal and connected, ascending or descending in size, and as constellations of spatially separated pieces. The conglomerate pieces are more than the sums of their constituent parts. The two examples I'll use are Tiny Catastrophes and Rig. These are the most sparse and the most exaggerated uses of the multiple rectangle construction.

Rig (figure 11) uses the multiple rectangle motif on two levels. First, it makes a statement about black and white by butting a (predominantly) black surface up against a (predominantly) white surface. Second, the four way division of the black surface against the undivided white surface says " $4: 1$ " or "1:4."

These simple visual statements systematically weave the piece together. Standing on their own (the black half and the white half were originally resolved 
as independent pieces), they have their own, separate, self contained "meanings." Connecting the pieces is an act like addition but their combined "meaning" is not arrived at additively. Symbiosis occurs. A larger system is implied. (The color black is certainly more different from the smell of cinnamon than it is from the color white.) Similarities and differences between its constituent parts accumulate into a greater meaning.

The other example of the multiple rectangle motif is Tiny Catastrophes. (Figure 2)

The connecting systems are diverse, and obscure. Tiny Catastrophes asserts "word against image, reproduction against thing, invented against appropriated, construction against painting, real against unreal (or hyperreal), before against after, right here against elsewhere, etc." Connections are established between such a wide array that a single, unified meaning is impossible. (unless it is taken to be a meta-meaning such as a single, unified meaning is impossible.) The system of interconnections and references is selfcontradictory. It aims for an exaggerated conceptual dissonance.

Tiny Catastrophes uses the multiple rectangle arrangement to stand against itself. The disharmony between the different sections and languages of the piece, however, is in agreement with the imagery and title - all alluding to a disaster of some kind. But now the internal disagreement has become agreement. The labyrinth has shifting walls.

How does meaning reside in this conceptual morass? If I knew the answer then I would not have made this piece. Tiny Catastrophes, like all the work in this body, is more of an investigation than an assertion. 


\section{Part Eight:}

Books

The book format is an extension of the multiple rectangle motif. The ultimate aims of the books are not dissimilar to the aims of the paintings. Each book's story (a sort-of story in a sort-of language), seeps in through some combination of internal and external reference. Connections are drawn poetically. Like the paintings, the exact aims are the different books are both unique and related. The book format appeals to me because it can address the issues that painting does in different ways.

The multiple rectangles of the book pages are more or less homogenous in size. Pages are treated as variations on a few intertwining themes. Unlike paintings, where there are many possible points of entry, the book unfolds in a fixed order. Their rhythm is incremental and one directional. Compositions of whole books (as opposed to single pages) are like poems or musical scores. While paintings layer patterns in space, the book layers in time. Successive pages act in harmony or discord with those that came before. The memory is engaged more directly. Expectations come into play as well. Images and applications reappear in long patterns or occur once and not again.

Each of the books has its own stories. $2+$ hours a day is about secrets. Babel is about noise. Iron Stars is about loss and distance. (As the universe slides towards heat-death, the gradual exhaustion of nuclear fuel drags matter inexorably towards iron. Elements more complex than iron undergo fission while the less complex undergo fusion. When all the suns are out, that will be the bulk of our universe - cold iron stars). Each tells its own story better. 
Each "story" make a sort of sense internally with rhythm, repetition, and implied parameters. It is the internal workings of your own mind to which the story-like situation connects. Its patterns and departures from patterns, its floating symbols and unfixed references are analogies to the orders (and disorders) of the perceptive process.

The book format also provides a natural way to work my writing into my visual art. It is difficult to work text into paintings. The written word is tremendously powerful. In painting, text often spins the work in uncontrollable directions. On the other hand, text integrates much more naturally with image in the context of the book. The appearance of both in conjunction is not unexpected. Text performs a layering in time like the composition of whole books. The internal rhythm of text speaks to the overall rhythm of the book. 
Part Nine:

Three Images

There are three recurring images that need discussion. They are the tangle, the hanging organic object, and architecture. All three of these have similar appeals to me.

conceptually

The tangle and the organic form both originated in telephone and notebook doodles. They have obvious external references but are used because they began to emerge from me when my mind was otherwise occupied. That unconsciousness gives them a special status. They are without a fundamental kind of meaning, almost emblematic of a lack of specific meaning.

The architecture imagery, likewise, stems from my subconscious. While obviously related to real architecture, it is mostly inspired by my dreams. Often my dream world is uninhabited and all I have are these uncertain, not quite euclidean structures. This source appeals to me, again, for its lack of a solid ground. As architecture appears in my art, it is referential to the unconscious.

These images stem from sources so personal or universal that I do not claim to fully grasp them. Using them, I am not reaching for a specific, objective interpretation.

Formally 
These three images all engage in a sort of double talk. The image of the tangle simultaneously invokes the illusion of volume and gives the impression of flat patterning. On one hand, it appears to refer to some exterior, three dimensional thing: an irregular weave of continuous threads going alternately over and under one another. On the other hand it seems to refer only to itself: a simple pattern of discontinuous line segments arranged within set parameters. It refers to the outside world and to itself in an ambiguous manner. It may suggest the convoluted paths of our bodies through the spaces we inhabit or the visual homogeneity of written language.

Likewise, the architectural shapes create the illusion of depth at points and work as flat, linear elements at others.

The hanging biomorphic shapes evoke abstract space (along with the color, mark, and scale relationships on the painted surface) while simultaneously asserting actual, physical spatial relationships. They violate the picture plane. The engagements of actual and illusory volume combine. 


\section{Part Ten:}

\section{Conclusion}

All this discussion, revolving around ambiguity, multiplicity, subjectivity, and meaning touches on what the work means and how it means what it does. But it is not the whole story. The whole story is the territory of which the map, by necessity, falls short. The work leaves reason behind in search of that other thing the unexpected occurrence of order in raging chaos. It ventures out into the grey area between meaningful and meaningless, between sense and nonsense. Lines are drawn and transgressed. Art must say that which can be said in no other way. Though Songs and Stories is partially about all of what has been discussed, it is also about something else.

These works are songs and poems, dances within the realm of possibility. They are about the tragedy, elation, and mystery of life. They are about remembering and forgetting, dreams of the ocean, the "great floods of $96, "$ the death of loved ones, and the cold of outer space. They are about things, languages in which things are discussed, and meta-languages in which languages are discussed. They are about the world in its multiplicity, ambiguity, and inconsistency.

Some lines from (Babel) Babble are:
"Insert device that cancels
Makes cancer in machines
in how many dialects
of how many languages 
map mixing in with the territory

shaky and unsure, quotes with nothing in them" 4 
Footnotes

${ }^{1}$ Mel Katz, in conversation (Tuesday, April 9, 1996)

${ }^{2}$ Ferdinand de Saussure, Course in General Linguistics, trans. Roy Harris (London, Duckworth, 1983)

3 Quote attributed to Hassan i Sabbah, William S. Burroughs, Apocalypse

(illustrated catalog of 20 silk screen collaborations with Kieth Herring), George Mulder Fine Arts, 1989

4 Matthew Haggett, Babble (artist's book, 1996) 
Figure 1

Songs and Stories that only you know

Two Installation Views

1996

Facing Southwest

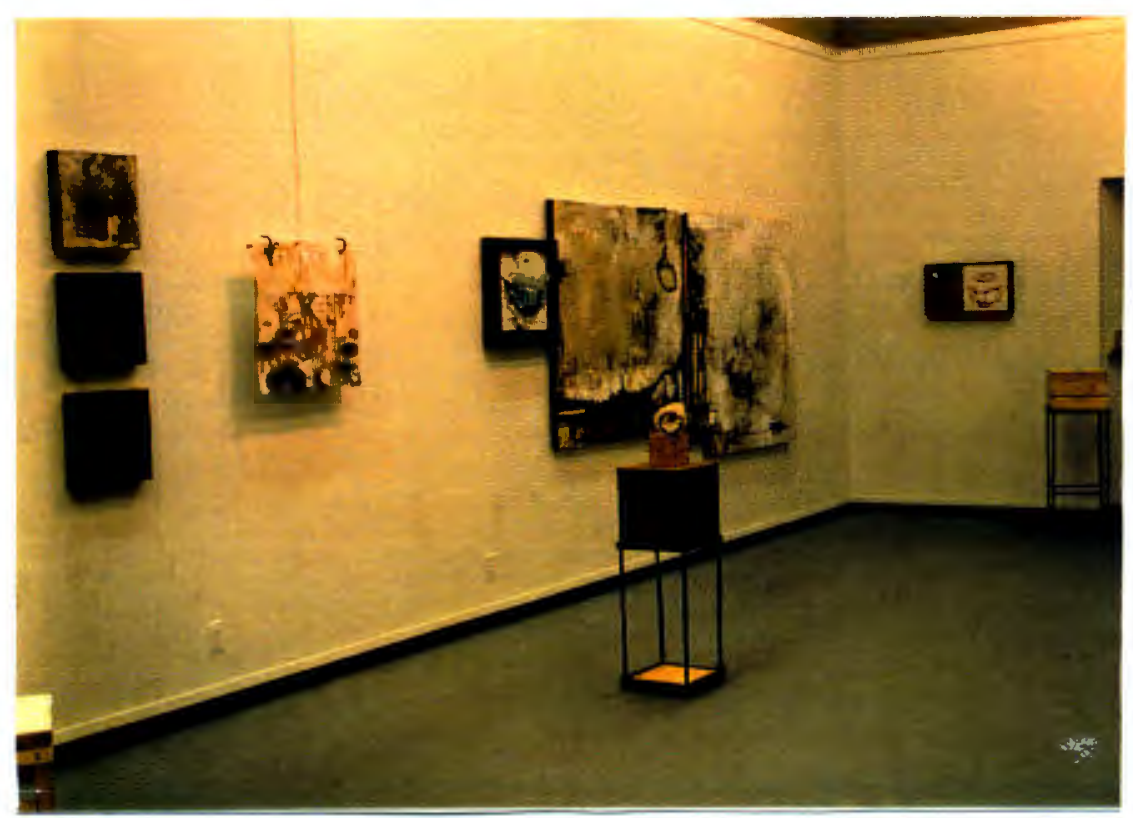

Facing Northeast

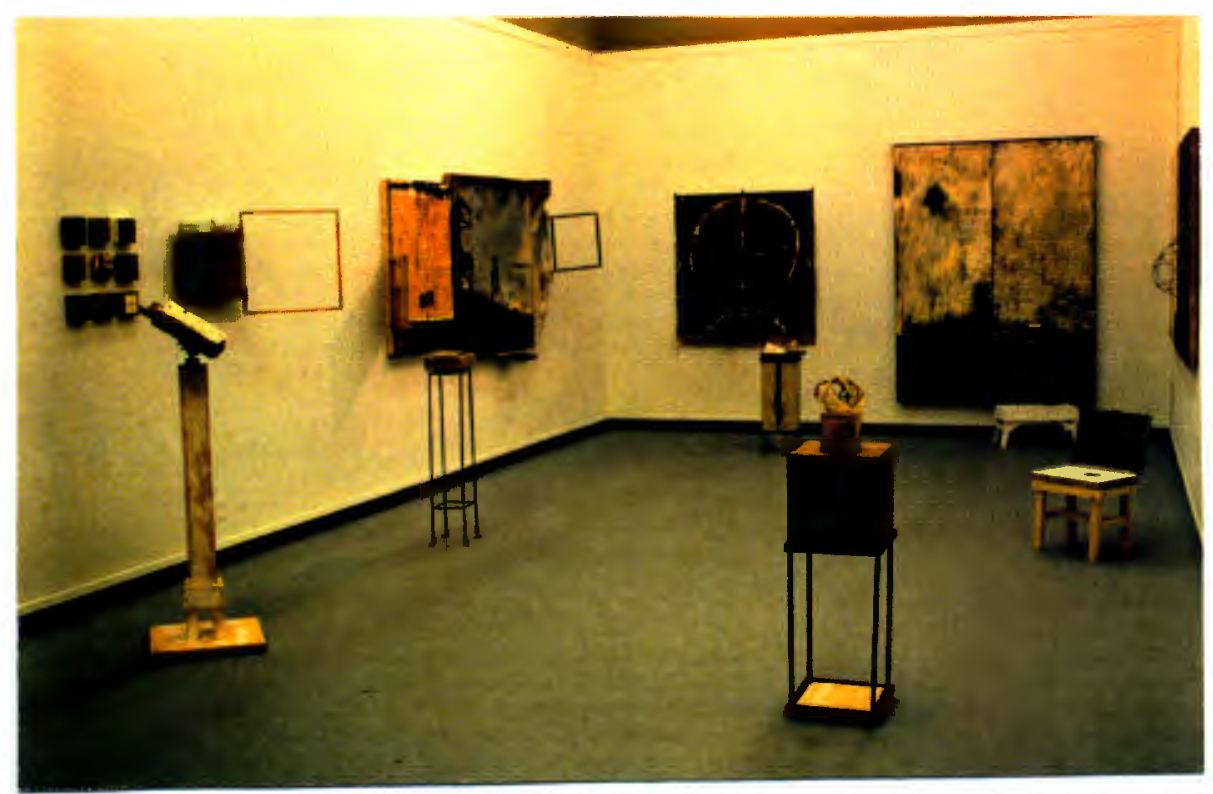


Figure 2

While We Were Sleeping 1996

Tar, Acrylic, Varnathane, Assemblage

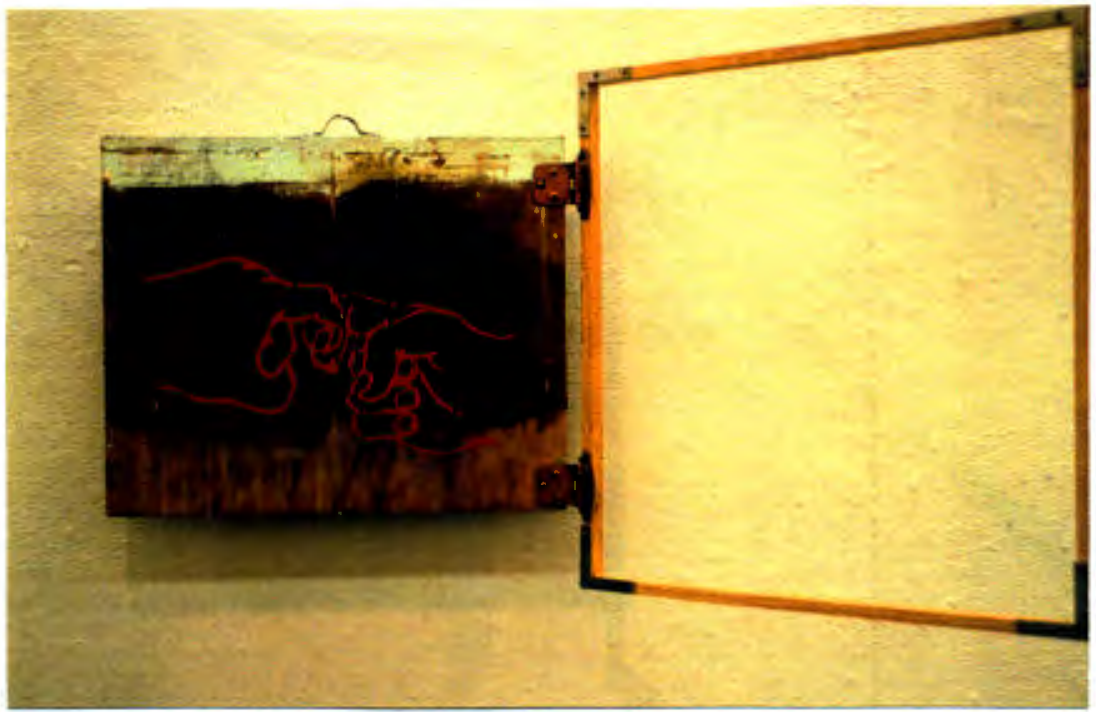

Figure 3

Tiny Catastrophes 1996

Acrylic, Latex, Tar, Oil, Encaustic, Acetone Transfer, Paper, Wood, Metal, Glass, Linoleum, Found

Photograph, Found Landscape Painting, Paint Brushes, Horse's Teeth

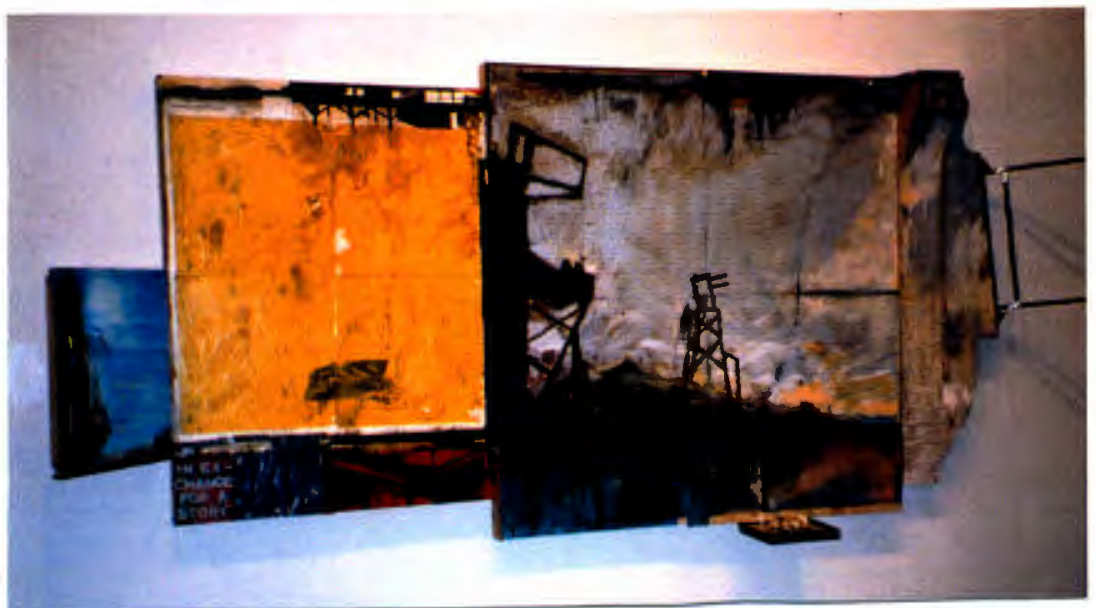




\section{Figure 4}

Back From After 1995

Encaustic, Acetone Transfer, Gold Foil, Found Paper, Wood, Tar, Varnathane

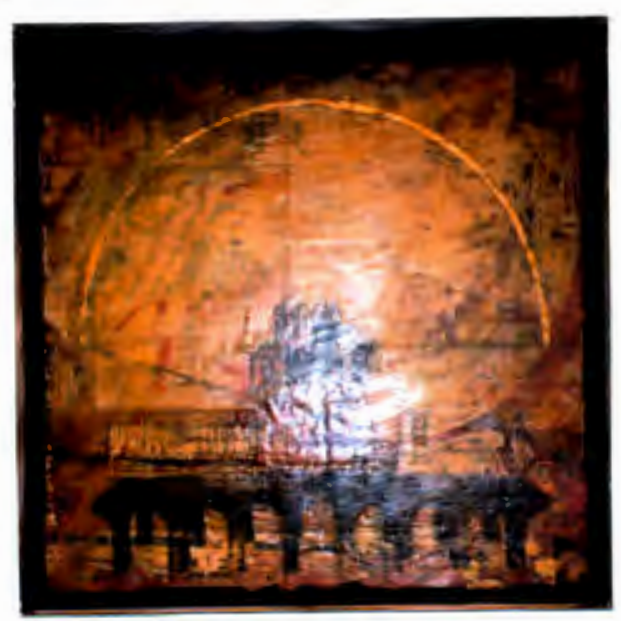

Figure 5

A Song for the Hawthorne Bridge 1995

Encaustic, Tar, Paper Collage, Wood

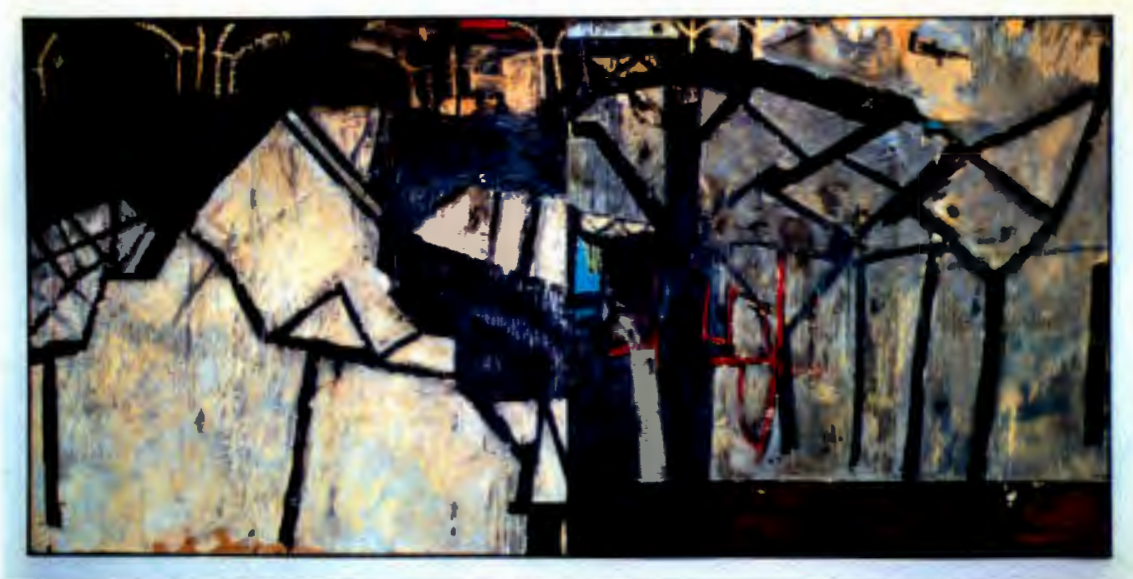


Figure 6

Threshold

Encaustic, Tar, Steel, Steel Wire, Lathe, Wood, Spackle, Latex, Varnathane, Twine 1996

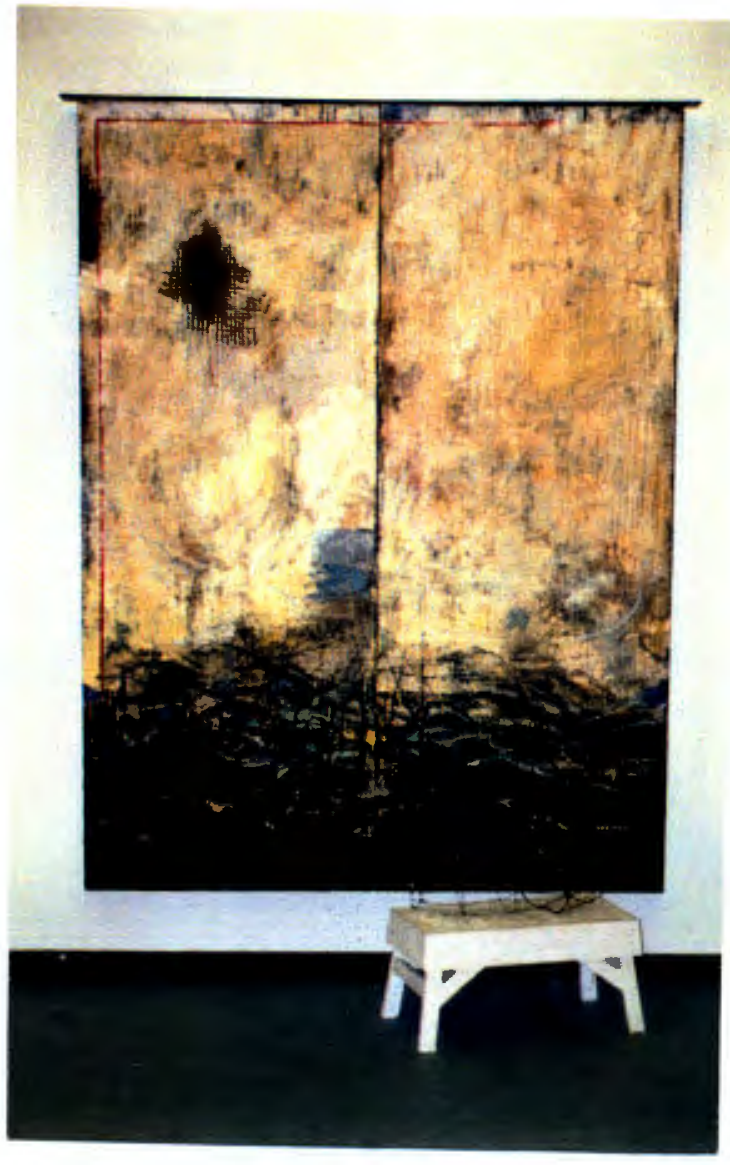



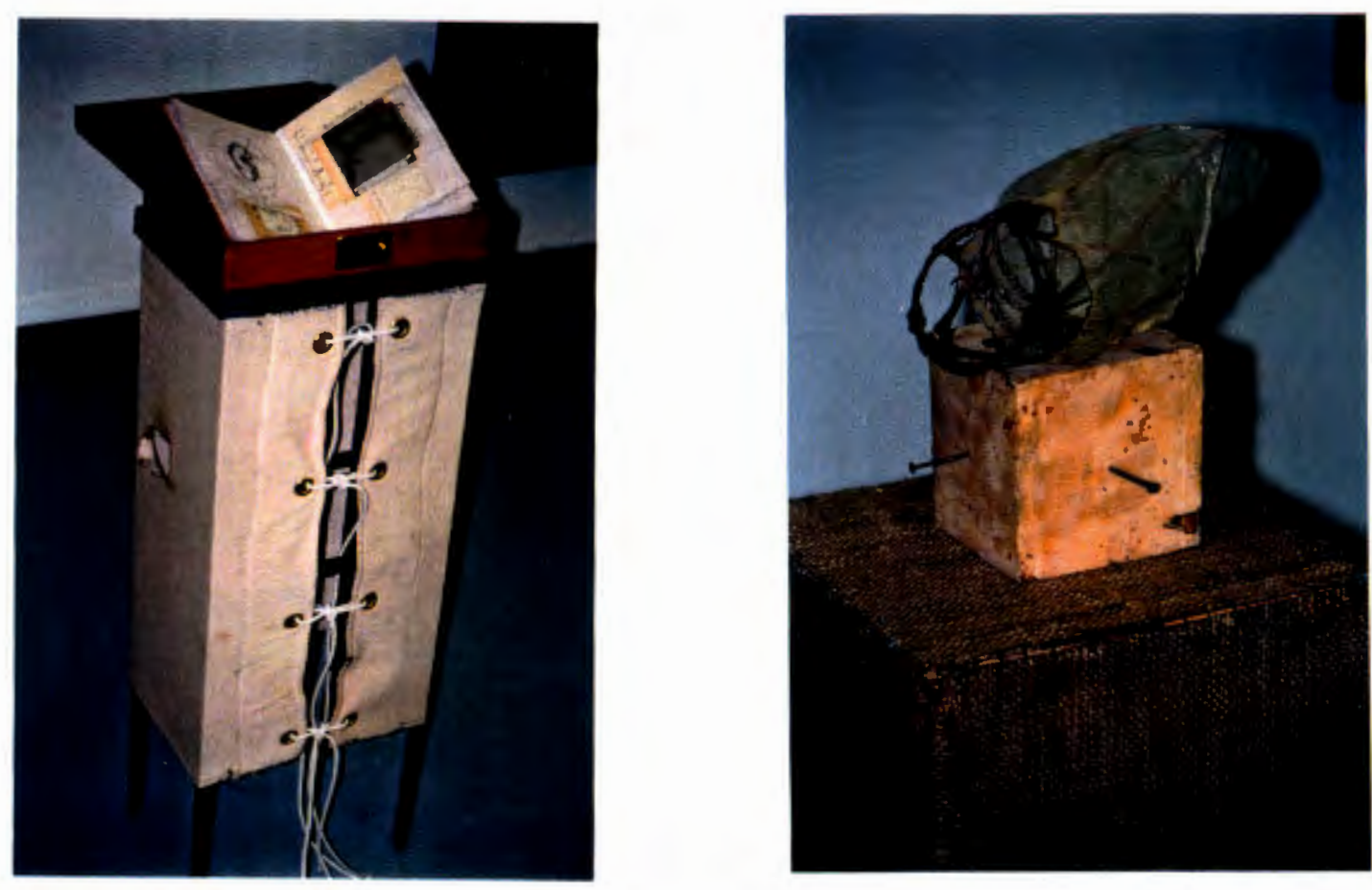

Figure 7

Evolution of Expression 1995 Book (Found Paper, Acetone Transfer, Gouache, Found

Steel Cover) In Found Box on Stand (Steel, Canvas, Twine)

\section{Figure 8}

False Remembering (detail) Steel Wire, Twine, Tissue Paper Varanthane, Burlap, Wood, 
Figure 9

2+ Hours a Day (detail) 1995

Paper Collage, Acetone Transfer, Ink, Acrylic, Gouache, Varnathane, Found Cover

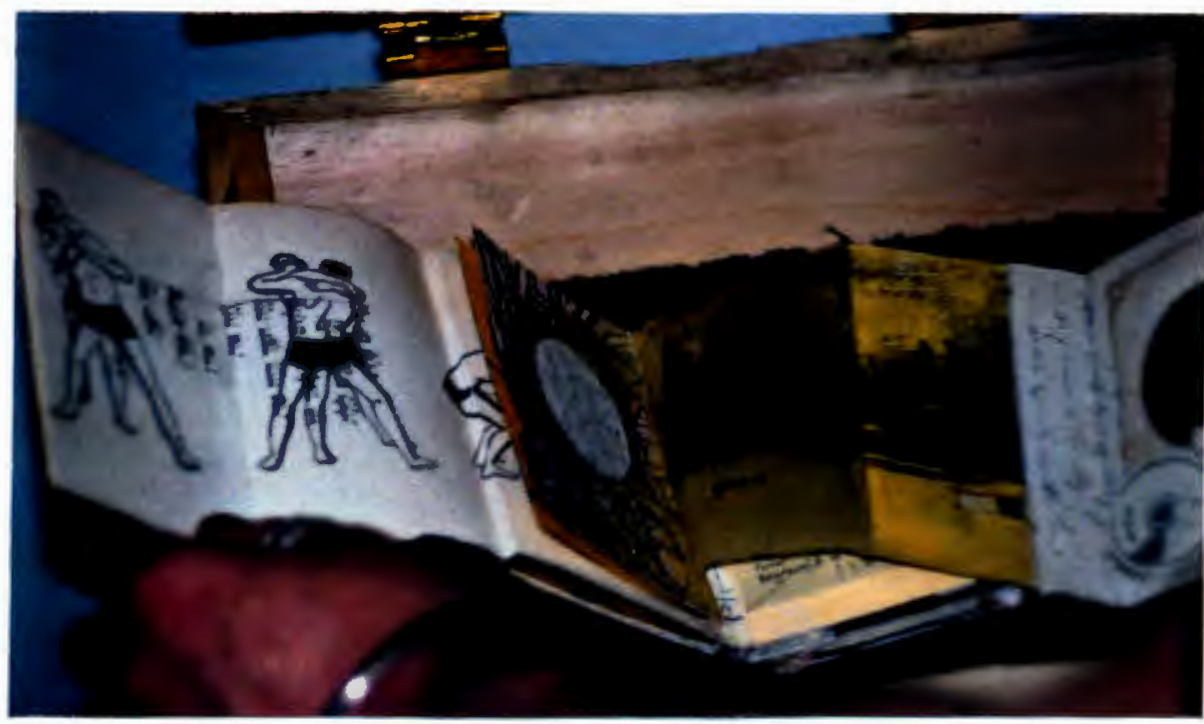

Figure 10

Dis 1995

Tar, Latex, Encaustic, Spackle, Blue Fabric, Steel, Found Globe, Found Metal, Paper Collage, Wood

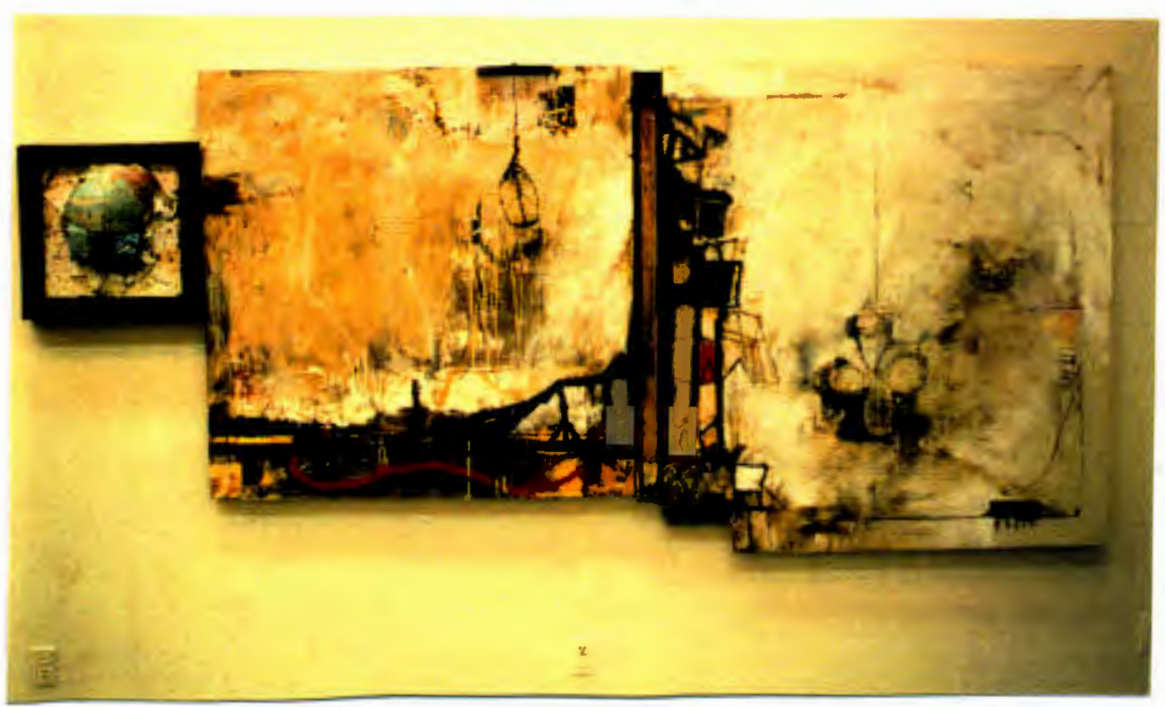


Figure 11

Rig 1994

Spackle, Acrylic, Wax, Paper Collage, Found Metal, Wood

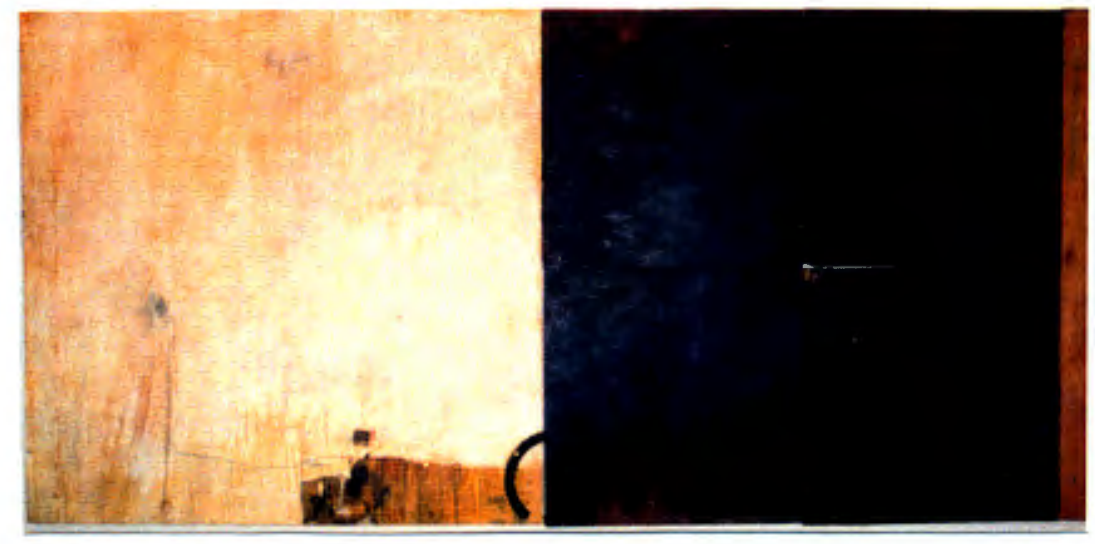

